\title{
Information in Action
}

Soft Systems Methodology 


\section{Macmillan Information Systems Series}

Series Editor: Professor I. O. Angell

Information in Action

Soft Systems Methodology

Lynda Davies and Paul Ledington

Information Systems Management

Opportunities and Risks

Ian O. Angell and Steve Smithson

Understanding Information

An Introduction

Jonathan Liebenau and James Backhouse 


\title{
Information in Action Soft Systems Methodology
}

\author{
Lynda Davies \\ Griffith University \\ Australia

\section{Paul Ledington} \\ University of Queensland \\ Australia
}

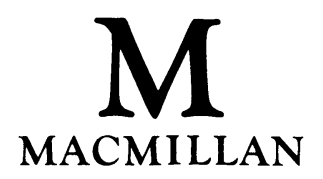


(C) Lynda J. Davies \& Paul W. J. Ledington

All rights reserved. No reproduction, copy or transmission of this publication may be made without written permission.

No paragraph of this publication may be reproduced, copied or transmitted save with written permission or in accordance with the provisions of the Copyright, Designs and Patents Act 1988 or under the terms of any licence permitting limited copying issued by the Copyright Licensing Agency, 33-4 Alfred Place, London WC1E 7DP.

Any person who does any unauthorised act in relation to this publication may be liable to criminal prosecution and civil claims for damages.

First published 1991 by

MACMILLAN EDUCATION LTD

Houndmills, Basingstoke, Hampshire RG21 2XS

and London

Companies and representatives

throughout the world

ISBN 978-0-333-56539-1 ISBN 978-1-349-12698-9 (eBook)

DOI 10.1007/978-1-349-12698-9

A catalogue record for this book is available from the British Library 
Dedicated to

Peter Stewart Walsh

and

David James Walsh 


\section{Contents}

Preface viii

Diagramming conventions $\quad$ xi

Acknowledgements $\quad$ xiii

1. Introduction 1

Part I. The learning process of soft systems methodology 9

$\begin{array}{ll}\text { 2. Soft systems methodology: an illustrative study } & 10\end{array}$

$\begin{array}{ll}\text { 3. Problem situations } & 30\end{array}$

$\begin{array}{ll}\text { Part II. Soft systems modelling } & 57\end{array}$

4. Modelling human activity systems: root definitions of relevant systems 58

5. Modelling human activity systems: generating models 84

$\begin{array}{ll}\text { 6. Comparison } & 105\end{array}$

$\begin{array}{lr}\text { Part III. Reflections } & 132\end{array}$

7. Using the methodology 133

$\begin{array}{ll}\text { 8. Reflecting on the learning process } & 158\end{array}$

$\begin{array}{ll}\text { Index } & 165\end{array}$ 


\section{Preface}

This book is intended primarily for students of the management of information. It is unlikely that this will place the book in any set discipline but rather should find it of use across a variety of courses. This variety is likely to include information systems specialists as well as those involved with management courses which treat information as a fundamental attribute of managerial life. The term 'student' is being used in its broadest sense as anyone seeking to learn about a topic, whether on a formal course or not. However, the aim has been to make this a textbook so that it should fit easily into semester courses, though it also supports shorter courses or even postgraduate courses of longer duration.

The primary purpose of the book is to enhance learning. This means that references and citations have been minimalized to the point of almost total exclusion. Instead, suggested readings are given at the end of each chapter or section. This should help those who wish to follow the ideas further. The learning is also enhanced by the inclusion of discussion issues and exercises at the end of each chapter. A further enhancement is in the way that an illustrative study is given at the beginning of the book and then reflected upon in later chapters.

This book explores a fundamentally different view of information from that presented in the majority of information systems texts. This view is that information is continually being created in social life as we try to make sense of our worlds. Learning and information are mutually dependent in this process. Managing information is a process which we do all the time in ordering and renegotiating our realities. The process of managing creates information, which in turn creates a process of managing. It is usually implicit and intuitive and this creates problems for us when we have to socially negotiate our meanings. We misunderstand because we cannot easily make explicit what the issues are with which we are struggling. In exploring this vision of managing information, we realize that more formal processes are needed for helping the sense-making process to become ordered and explicit. One such process is in the form of a methodology which adopts a view of social reality creation and management that is highly compatible with our views on managing information. This is soft systems methodology. We take readers through that methodology so that they can learn it in order to apply it to the managing of information as a learning process.

The Introduction challenges current views of information management by arguing that management is a learning process which we carry out all the time. The main problem is that we need to make the process more explicit so that we 
can better understand what is going on. In this way, information management becomes the management of the learning process and soft systems methodology is introduced as an approach for helping that learning process. The role of information technology is also discussed.

In Part I, we look at The learning process of soft systems methodology and work through this by looking at an illustrative study which is an account of one author's use of the methodology. This provides the initial understanding of the methodology which is then looked at in greater depth as the concept of Problem situations is introduced. It is here that we look at culture, politics, roles of intervenors, and the notion of problems as social attributes created in a social world of sense-making. This sets the context of an understanding of social reality that is fundamental both to soft systems methodology and to the explanation of managing information which the book presents. In this section the story of an intervention using soft systems methodology is unfolded. It is treated in a personalized manner as is commonplace in accounts of interventions using a phenomenological view of the social sciences. This is the view adopted throughout the book but which is most obvious in this section.

Part II moves onto the technical aspects of carrying out the methodology in a rigorous and defensible manner. It is here that Soft systems modelling is concentrated on. The fundamental concept of a soft systems model is that of the human activity system. This is generated through two technical operations which are presented in detail in the chapters Modelling human activity systems: root definitions of relevant systems and Modelling human activity systems: generating models. Relevant systems are chosen, that is, ideal type systems which are relevant to learning about the problem situation. These are then developed into core descriptions which are called root definitions. These each express a particular world view. The descriptions are then translated into models of human activity systems which represent the actions expressed in the root definitions. This means that the activities associated with the different world views can be understood and this provides the groundwork for the next stage, namely Comparison of the models with the real world problem situation. Comparison is the most powerful part of the methodology, as it is here that learning occurs in the process of gaining clarity regarding the different views in the situation.

Part III deals with Reflections. Here the learning which has hopefully occurred throughout the reading of the book is challenged and developed. The 
first way in which this is done is to return to the illustrative study, revisiting it by looking at the reality of Using the methodology. It is too easy to believe that a methodology will bring about answers all by itself. It cannot, and this is discussed in the chapter. Every situation has different issues and this should cause reflection on the part of the practitioner, who is trying to make sense of the situation and to help those within it to understand what is happening and what can be done. This chapter tells the 'warts-and-all' version of a particular intervention. The aim is to provide an experiential account which may help naive users to avoid the painful process of expecting too much of a methodology, and so avoid the likelihood of being let down as a result. The chapter aims to help by highlighting the fact that often the situations which are read about will have had traumatic problems, but all recording of these will normally have been removed. Academic authorship in learned journals regularly requires this depersonalization. However, learning can come from these traumas and so they are worthy of attention. It helps the discovery process to see what actual problem situations can be like. It also prevents the feeling of failure, which may not be justified. Getting into difficulties is not necessarily a failure and this is discussed in a somewhat reflective manner. The final chapter takes a stance of Reflecting on the learning process. This leads the reader back to arguments given in the introduction and revisits the view of managing information given there, expanding upon it. The manager of information acting as a guide for the learning process is the central theme of the chapter. The methodology is reflected upon in the light of this, as the different sections of the book are briefly revisited. Whilst reflection is the theme of this section, it is the notion of managing information which is the main argument of this book and the book concludes by re-examining this.

Information systems as a discipline is a hybrid which is attached to many other disciplines. This is probably not a bad thing. Information is central to our lives, therefore we cannot avoid it. We can choose to study it in expressed forms and through particular frameworks but we cannot pinpoint it down to a set area of study, or at least attempting to do so may be futile, if not potentially destructive. Taking the management of information seriously as a continual daily social process is central to our message. Soft systems methodology is a framework for enhancing that process by improving learning. We hope that this book helps the reader to understand that message and to improve the creation and management of information as a result of the learning process. 


\section{Diagramming conventions}

In soft systems methodology there is a heavy reliance upon diagramming as a means of expression and communication. The diagramming has some formal conventions and some informal. The use of diagrams is also a major element in the general field of information systems modelling, but there the conventions are very much different from those of soft systems methodology. In order to prevent any confusion, the conventions for all diagram types in soft systems methodology that are used in this book are given below:

\section{Rich Pictures}

The purpose of rich pictures (e.g. figure 2.3) is to provide an aide-mémoire for gaining an appreciation of the problem situation. Rich pictures are of the form of free artistic expression, and are intrinsically individualistic in their expressive style. Basically, there are no conventions of diagramming, except one, and that is that no systems models or systems maps are used at the rich picture stage. All arrows and boxes are merely artistic expressions - they are not, repeat not, conventional forms.

\section{Diagrams}

These are used as an explanation in pictorial form of the flow of an argument. They are not models of systems as such. Diagrams of the summary description of the methodology (e.g. figure 2.1) are of this form. They simply present the written text as a series of statements which flow in the form of a logical argument. An arrow means "leads to", and a box, polygon or oval means "a descriptive statement".

\section{Conceptual models}

It is in this type of diagram (e.g. figure 5.6) that the formal conventions of soft systems modelling apply. All the aspects of a conceptual model are rule-based and meaningful in conventional terms. The thinner arrows mean "logical relationships", thicker arrows mean "commodity inputs and outputs". Boxes, polygons and ovals mean "activities". When more than one activity is boxed together then this box represents a sub-system. Zig-zag arrows show a logical relationship to, or from, all parts of the system. 


\section{Acknowledgements}

This book is the result of a continual learning process, lasting around a decade, that has engrossed the authors. The wider learning context has been going on for over twenty years at the Department of Systems and Information Management at Lancaster University, U.K. We are extremely grateful to the members of that department for the creation of a learning context and for providing the means whereby we could flourish in our associative learning with them. Peter Checkland is a key member of that department and did much more than simply provide learning. He and Glen Checkland have provided valuable friendship, which has led to many of the reflections making this book possible.

We are also grateful to our soft systems community around the world who have been part of the clarification process needed for this book to happen. The other primary player is the cheery-natured Welshman whose intellectual residence is LSE. Ian Angell contrived this book out of us and for this we are very grateful. We are also grateful to Griffith University and the University of Queensland for providing the necessary support and to the many students who have challenged us and helped us along the way. Special thanks also go to our colleagues and friends Tim Davis and Sue Nielsen.

Finally, we want to acknowledge the debt owed to our family. We have only one combined family as we are in the unusual position of being joint working spouses. Thanks, Mum, David and Peter. And Lynda says 'thank you' to her husband Paul, the same as Paul says 'thank you' to his wife Lynda. 